\title{
Alüviyal fizyografyalar üzerinde gelişen farklı topraklarda arazi değerlendirme çalışmaları
}

\section{Land evaluation studies on different soils developing on alluvial physiographies}

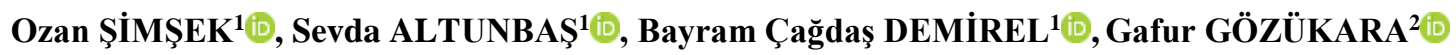

${ }^{1}$ Akdeniz Üniversitesi, Ziraat Fakültesi, Toprak Bilimi ve Bitki Besleme Bölümü, Antalya

${ }^{2}$ Eskişehir Osmangazi Üniversitesi, Ziraat Fakültesi, Toprak Bilimi ve Bitki Besleme Bölümü, Eskişehir

Sorumlu yazar (Corresponding author): S. Altunbaş, e-posta (e-mail): saltunbas@akdeniz.edu.tr

Yazar(lar) e-posta (Authore-mail): oznsimsek@hotmail.com, cagdasdemirel@akdeniz.edu.tr,ggozukara@ogu.edu.tr

\section{MAKALE BİLGİSİ}

Alınış tarihi 21 Ağustos 2019

Düzeltilme tarihi 05 Kasım 2019

Kabul tarihi 14 Kasım 2019

\section{Anahtar Kelimeler:}

Alüviyal araziler

Arazi yetenek sinıflaması

Toprak etüd haritalama

\section{ÖZ}

Her geçen yıl tarımsal arazilerin toplam araziler içindeki oranı gittikçe azalmakta, tarım alanlarımız birçok yerde amacının ve yeteneğinin dışında, plansız bir şekilde kullanılmaktadır. $\mathrm{Bu}$ çalışmada, tarımsal üretim için kıymetli sayılan alüviyal araziler, materyal olarak seçilmiştir. Bu amaçla, Antalya ili Aksu ilçesinde yer alan Solak köyünün alüviyal arazileri, gelecekte yapılacak ideal arazi kullanım planlamaları ile tarımsal veya tarım dışı, her türlü kullanım kararlarında kullanılmak üzere incelenerek değerlendirilmiştir. Toplam 1625.3 ha' lık çalışma alanına ait topografik haritaların, hava fotoğraflarının, uydu görüntülerinin incelenmesi ve arazi değerlendirmeleri sonucunda, 3 farklı fizyografik ünite tespit edilmiștir. Taşkın düzlüğ̈̈, nehir sırtı ve yan dere alüviyali olarak belirlenen fizyografik üniteler üzerinde ise birbirinden farklı toplam 8 adet toprak serisi tespit edilmiștir. Toprak serilerinden Atçayırı, Batem 1, Expo, Kelbük, Körcegözler ve Mısnar serileri taşkın düzlüğünde, Solak serisi nehir sırtı üzerinde, Batem 2 serisi ise yan dere alüviyal fizyografyaları üzerinde belirlenmiş̧ir. Çalışma alanında $250 \mathrm{~m} \times 250 \mathrm{~m}$ aralıkla 259 grid noktası ișaretlenmiş ve her bir noktanın seri+faz düzeyinde haritalama birimleri tanımlanmıştır. Ardından her bir haritalama birimine bağlı arazi yetenek sınıfları tespit edilmiștir. Çalıșma alanında arazi yetenek sınıflamasının sadece I., II. ve III. sinıflarına sahip araziler tespit edilirken, II. ve III. sınıf arazilerde toprak tekstürüne (s) ve/veya drenajına (w) ilişkin sorunlar olduğu bulunmuştur. Çalışma alanı içerisindeki farklı arazi yetenek sınıflarının haritalandırılmasıyla sonuçlanan bu çalışma da arazilerin yetenekleri dışında kullanımlarına engel olmak için bilimsel bir dayanak oluşturulmaya çalışılmıştır.

\section{ARTICLE INFO}

Received 21 August 2019

Received in revised form 05 December 2019 Accepted 14 December 2019

\section{Keywords:}

Alluvial lands

Land capability classes

Soil survey and mapping

\section{ABSTRACT}

Year after year, ratio of agricultural lands in total land areas have been progressively decreasing and agricultural areas in many places are planlessly used out of their purpose and capacity. In this study, alluvial lands considered as valuable for agricultural production were selected as material. For this purpose, alluvial lands of Solak village, which is located in Aksu district of Antalya, have been evaluated for use in all kinds of agricultural or non-agricultural usage decisions with ideal land use planning to be made in the future. As a result of the analysis of topographic maps, aerial photographs, satellite images and land evaluations 3 different physiographic units were identified in total 1635.3 ha study area. Eight soil series apart from each other were detected on these three different physiographical units identified as floodplain, river bank, and tributary river. Soil series of Atçayırı, Batem 1, Expo, Kelbük, Körcegözler ve Misnar involved in floodplain while Solak series and Batem 2 series involved in river bank and tributary river alluvials, respectively. In the study site, 259 grid points were assigned by $250 \mathrm{~m} \times 250 \mathrm{~m}$ ranges and mapping units of each point were identified at level of series+phase. After that land capability classes depended on each mapping units were determined. While fields having only I., II. ve III. capability class were detected, problems associated with soil texture and/or drainage were defined for II. ve III. ability class of fields. In this study resulting in mapping of different field ability classes in the study site, a scientific basis was generated to prevent inappropriate use of fields by their ability classes. 


\section{Giriş}

İnsanlığın var oluşundan bu yana artarak devam eden kaynak kullanımı, gelecek için çevresel endişeleri de arttırmaktadır. Her geçen gün küreselleşen dünyada doğal kaynak kullanıcılarının üzerinde durması gereken en önemli nokta, kaynakların kullanmanın tahrip edici şekilde değil, sürdürülebilirliğini sağlayacak bir anlayış içinde ele alınması ve yönetilmesi gerektiği belirlenmiştir (Baykal ve Baykal 2008). Sürdürülebilir kullanım planlamaları, kaynakların korunmasını sağlarken aynı zamanda arazilerin kullanım planlamalarının da oluşturulmasına imkan sağlamış olacaktır.

Arazi kullanım taleplerindeki artış ve bununla birlikte arazi kullanım planlamalarının yapılmaması, hatalı arazi kullanımlarını beraberinde getirmektedir. Hatalı arazi kullanımları, kısa vadede kullanıcılara ekonomik fayda sağlasa $\mathrm{da}$, bu hatalar toprakları olumsuz yönde etkilediğinden geri dönüşümü bazen imkansız sonuçlar ile karşılaşılması, kaçınılmaz olduğu bildirilmektedir. (Demirel 2017). Günümüzde araziler ve onun en temel unsuru olan topraklar diğer pek çok amaçla birlikte, öncelikle ya ideal kullanım biçimlerinin belirlenmesi, ya da toplulaştırma ve dağıtma işlemlerinin rasyonel uygulanabilmesi için değerlendirmeye ve planlamaya tabi tutulurlar. İdeal arazi kullanım planlamasını gerçekleştirebilmek için öncelikle arazi değerlendirmesi çalışmalarını yapmak gerekmektedir (FAO 1985, Şenol ve Tekeş 1995).

Arazide yapılacak toprak etüd haritalama ve değerlendirme çalışmaları sonunda üretilecek olan arazi yetenek sınıflaması haritasının istatiksel olarak da bir anlam kazanması ve uzman görüşlerinin etkisini azaltacak şekilde farklı jeoistatiksel modellerin kullanılması elde edilen sonuçların objektif değerlendirilmesine yardımcı olacaktır. Faklı jeoistatiksel modellemelerinde kullanılacağı toprak bilimi çalışmalarında en uygun tahmin modelinin kriging metodu olduğu bildirilmiştir (Karaman ve ark. 2012). Fakat topraklar çok kısa mesafelerde bile değişkenlikler gösterebildiği için istatiksel metodların değerlendirilmesinde diğer bilim dallarına göre toprak biliminde daha dikkatli olunması gereklidir (Koca 2014).

Coğrafi Bilgi Sistemleri tabanlı geomatik yaklaşımlarla hazırlanan toprak haritalama çalıșmalarında arazi ve toprak arasındaki ilişkiyi kullanarak toprak özelliklerinin tahmin edilmesiyle oluşturulan arazi yetenek sınıfi tabloları referans alınarak arazi birimleri haritaları ve toprak yetenek haritalarının üretilebileceği savunulmuştur (Vacca 2014).

Topraklar, yeryüzündeki karasal ekosistemin, en önemli doğal kaynak değerlerinden bir tanesidir. Sadece canlı varlıklar için değil, aynı zamanda içme suyunun temizlenmesinde ve depolanmasında, su döngüsünde, insanlara ve bitkilere besin maddesi temininde ve barınak olmasında, aynı zamanda sanayide hammadde olarak kullanılmasinda vb. daha sayllabilecek pek çok fayda ile kritik bir öneme sahiptir. Ana materyal, topoğrafya, iklim, zaman ve biyolojik faktörlerin bir arada çalışmasıyla yüzlerce veya binlerce yılda oluşabilen topraklar, maalesef birkaç gün veya saatte kaybedilebilmektedirler. $\mathrm{Bu}$ kayılar erozyon gibi doğal sebeplerle olabildiği gibi hatalı veya amaç dışı arazi kullanımı gibi insan kaynaklı sebeplerle de olabilir. Toprakların kirletilmesi ve/veya verimsizleştirilmesi de bir diğer önemli toprak sorunu olarak nitelendirildiği ortaya konmuştur (Altunbaş ve ark. 2017). Toprak sınırlı ve değerli bir kaynaktır. $\mathrm{Bu}$ nedenle toprakların yetenek ve niteliklerinin belirlenmesi ve arazi kullanım planlamalarının yapılması gerekmektedir (DPT 2005).

Arazi kullanım planlamalarının belirlenip, toprakların doğru yönetimi için öncelikle arazilerin detaylı olarak etüd edilmesi ve haritalanması gerekmektedir. Arazi ve toprakların tanımlanabilmesi, o bölgeyi oluşturan jeomorfolojik güçlerin etkisi ile oluşan fizyografyanın doğru şekilde yorumlanmasıyla mümkün olduğu bildirilmektedir (Sarı 2015; Gözükara 2019; Gözükara ve ark. 2019). Tarımsal üretim için, verimli toprakların bulunduğu yerler olarak kabul edilmesinin yanı sıra, gerek ülkemiz ve gerekse dünya gıda güvenliği ve devamlılığ açısından stratejik bir öneme sahip olan alüviyal tarım arazilerinin, farklı fizyografik ünitelere sahip oldukları bilinmektedir.

$\mathrm{Bu}$ noktadan hareketle, Antalya ili Aksu ilçesi Solak köyünde, tarımsal potansiyeli yüksek alüviyal depozitler üzerinde gelişen ve detaylı toprak etüdleri yapılan arazilerin, yetenek sınıflarının belirlenmesi, tematik haritalarının oluşturulması, hatalı arazi kullanımlarının önüne geçilmesi ve gelecekte arazi kullanım planlamalarının oluşturacak kullanıcılar için bir altlık bilgi sağlanması hedeflenmiştir.

\section{Materyal ve Yöntem}

\subsection{Materyal}

$\mathrm{Bu}$ çalışma Antalya ili, Aksu ilçesi sınırları içerisinde yer alan Solak köyünde, 1625.3 ha'llk bir alanda yürütülmüştür. Çalışma alanı Tehnelli deresinin Aksu çayına birleştiği yerin kuzeyinde bulunmaktadır (Şekil 1). Solak köyü aynı zamanda DSİ 13. Bölge Müdürlüğü tarafından Aksu Çayı Taşkın Koruma ve Arazi Toplulaştırma Projesi kapsamında da yer almaktadır.

Araştırma alanını oluşturan alüviyal araziler üzerinde farklı toprak gruplarının tespitinin yapılması için açılacak olan profil noktalarının tespitinde Harita Genel Komutanlığ 1 (HGK) tarafindan üretilen 1/25000 ölçekli topografik haritalar, 1981 ve 1992 yıllarına ait hava fotoğrafları, 2016 tarihli Sentinel uydu görüntüsü $(10 \mathrm{~m})$, Tapu Kadastro Genel Müdürlüğ̈̈ (TKGM) tarafindan üretilen ortofotolar $(30 \mathrm{~cm})$ ve Maden Tetkik Arama Genel Müdürlüğü (MTA) tarafindan üretilen 1/25000 ve 1/100000 ölçekli jeoloji haritaları temel kartografik materyal olarak kullanılmıştır.

Gerek arazide gerekse büro çalışmaları sonucunda elde edilen verilerin birleştirilerek veri tabanı oluşturulması ve bu bilgilerin 1şı̆̆ında tematik haritaların üretilmesi için ArcGIS 10.2 programı kullanılmıştır.

Tipik Akdeniz iklim kuşağında yer alan çalışma alanında ortalama yıllık yağış miktarı $1068 \mathrm{~mm}$ olup, yağışlar yağmur şeklinde ve çoğunlukla ilkbahar ve kış mevsimlerinde düşmektedir. Yıllık ortalama sıcaklık ise $18.4^{\circ} \mathrm{C}$ 'dir. Toprak taksonomisine göre (Soil Survey Staff 1998) araştırma alanının toprak nem rejimi Xeric, $50 \mathrm{~cm}$ 'deki yıllık ortalama toprak sıcaklığının $15-22^{\circ} \mathrm{C}$ arasında olması nedeniyle toprak sıcaklık rejimi de Thermic olarak sınıflandırılmıştır.

\subsection{Yöntem}

Kartografik materyaller kullanılarak olası farklı toprak serilerini gösterecek profil noktalarının yerleri, fizyografik ünitelerin tespiti ve yorumlanması ile belirlenmiştir (Şekil 1).

Yapılan yorumlamalar sonucunda açılan profiller seri düzeyinde sınıflandırılmıştır. Her bir toprak serisindeki 


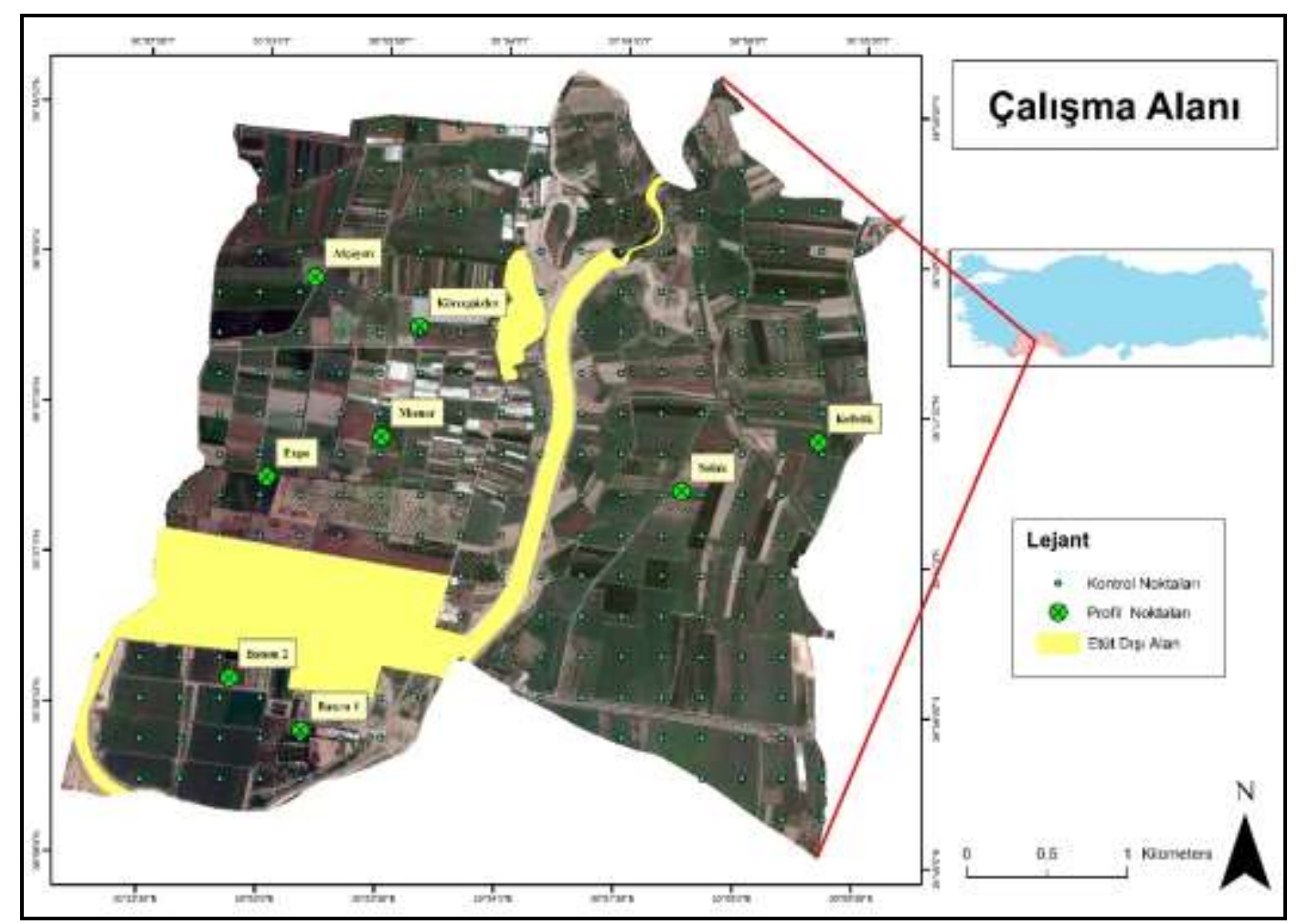

Şekil 1. Solak köyü çalışma alanı, profil ve kontrol noktaları.

Figure 1. Solak village working area, profile and control points.

profillerde horizon esasına göre horizon alt ve üst sınır derinliği, renk, tekstür, kıvam, özel görünümler (kütan, kayma yüzeyi, kireç birikimleri vb.), kök dağılımı, taşlılık ve horizon sınırları belirlenerek profil tanımlamaları yapılmıştır (Soil Survey Staff 1993; Dinç ve Şenol 2013). Tanımlamış her toprak serisinin, üst toprak tekstürü, eğim, drenaj, taşlılık, fazlarının olması gerektiğine karar verilerek haritalama lejantı hazırlanmıştır.

Profil başında morfolojik tanımlamaları yapılan horizonlardan, tekstür (Bouyoucos 1951) ve kireç (Schlichting ve Blume 1966) analizinde kullanmak üzere 46 adet toprak örneği horizon esasına göre alınmış ve analizi yapılmak üzere laboratuvara sevk edilmiştir. Araştırma alanında yer alan toprak sınırlarının belirlenmesinde ve bu sınırların çizilmesinde, grid (1zgara) yöntemi kullanılmıştır (Şekil 1). $250 \mathrm{~m}$ x $250 \mathrm{~m}$ aralıklarla çizilen gridlerde yapılan tanımlamalar sonucunda, 259 noktanın seri+faz düzeyindeki haritalama birimleri oluşturulmuştur.

Her bir haritalama biriminin, sahip olduğu üst toprak tekstütü, eğim, drenaj ve taşlılık gibi faz özelliklerinin düzeyine göre yetenek sınıflaması yapılmıştır. Teknik bir sınıflama sistemi olarak kabul edilen arazi yetenek sınıflamasına göre, çalışma alanında yer alan her bir haritalama birimi, öncelikle yetenek siniflarına, daha sonrada yetenek alt siniflarına ve yetenek birimlerine göre sınıflandırılmıştır. Toprakların yetenek alt sinıflamasinda kullanılan argümanların topraktan ve sudan kaynaklandığı belirlenmiştir. Toprak ile ilgili sınırlayıcılar (tekstür, eğim, taşl1lık) "s" ile kültür bitkilerinin gelişmesine engel olan su (yüzey ve derin drenaj taşkın zararı ve tehlikesi) ile ilgili sınırlayıcılar ise " $w$ " ile ifade edilmiştir.

Arazi yetenek sınıfları belirlenen her bir haritalama birimi için veriler, ArcGIS 10.2 yazılımında, haritalar üzerine öznitelik verisi olarak eklenmiştir. Öznitelik verisi olarak eklenen yedi farklı arazi yetenek sınıfi, ArcGIS yazılımının "Geostatistical Analyst" modülünden en düşük hata oranını (RMS) veren "kriging - ordinary" metodunun "exponential semivariogram" yöntemine göre, tahmini arazi yetenek sınıflaması dağılımını gösteren bir harita oluşturulmuştur. Ardından jeoistatistiksel analizin verdiği sonuçların da dikkate alınmasıyla çalışma alanına ait yüksek doğruluklu arazi yetenek sınıflaması haritası oluşturulmuştur.

\section{Bulgular ve Tartışma}

\section{1. Çalışma alanı genel toprak özellikleri}

Çalışma alanı için yapılan büro, arazi ve laboratuvar çalışmaları sonucu elde edilen bulgular 1şı̆̆ında hava fotoğrafları ve uydu görüntülerinin de yorumlanmasıyla Detaylı Temel Toprak Haritası oluşturulmuştur. Yapılan büro ve arazi çalışmaları sonucunda çalışma alanında 3 farklı fizyografik ünite ve 8 farklı toprak serisi tanımlanmıştır. Bu fizyografik üniteler; taşkın düzlüğü, nehir sırtı ve yan dere alüviyalleridir. Kuvarterner dönemin ürünü olan ve toprak oluşumunun devam ettiği bu alüviyal depozitler üzerindeki araziler, denizden yaklaşık 9-12 m yükseklikte düz- düze yakın topoğrafyada bulunmaktadırlar. Havzanın kuzeyinden güneye doğru akan aksu nehri ve düzlüklere çıkan birçok yan dere kolları, havzadaki toprakları etkilemiştir. Değişik dönemlerde farklı debilerle akan akarsu ve dereler kendi alüviyal yelpazelerini oluşturmuş, bu durumda fizyografik olarak toprak profillerinde karışmalara neden olmuştur. Çalışma alanı içerisindeki akarsu sistemlerinin taşıdıkları materyallerin niteliğine ve depoladığı yerlerin uzaklığına göre tekstürel farklılıklar görülmektedir. Akarsu veya derelerin ilk taşkın yaptığı, yatağa yakın bölgelerde daha kaba tekstürlü materyaller görülür iken, akarsu yatağına daha uzak noktalarda ise genellikle derin killi 
depozitlere rastlanmıştır. Bu nedenle aksu havzasının alt zonunu oluşturan çalışma alanında, birbirinden farklı toprak serileri tespit edilmiştir. Aşağıda taşkın düzlüğü ve nehir sırtı ve yan dere alüviyal fizyografyaları ve özellikleri verilmiştir.

Aksu Çayı ve Tehnelli Dereleri yakın geçmişe kadar yaptığı taşkınlarla yüksek arazilerden getirdikleri malzemeleri taşkın düzlüğü fizyografyası üzerinde depolamışlardır. Bu fizyografik ünitedeki araziler düz veya düze yakın bir topografyada bulunmaktadır. Taşınıp depolanan malzemelerin tekstürel yapısının ince olması sebebiyle, bu fizyografik ünite üzerindeki toprak serilerinde, değişik şiddetlerde drenaj sorununa rastlanılmaktadır. Ayrıca bu arazilerin, toprak gelişim prosesleri yeterince çalışamadığı için, A-C horizon dizilimine sahip kireçli topraklardır. Yapılan toprak tanımlama çalışmalarında taşkın düzlüğü fizyografyası üzerinde 6 farklı toprak serisi tespit edilmiştir. Bu seriler; Batem 1, Expo, Misnar, Körcegözler, Atçayırı ve Kelbük toprak serileridir. Tespit edilen toprak serilerine ait arazide yapılan morfolojik tanımlar ve laboratuvarda yapılan bazı analiz sonuçları Çizelge 1'de verilmiştir. Çalışma alanında taşkın düzlüğü fizyografyası üzerinde yer alan seriler, çalışma alanının \%73.5'nde (11949.9 da) yayılım göstermektedir. Toprak serilerinde renk, farklı zamanlarda ve farklı malzemelerin taşınıp depolanmasına bağlı olarak 2.5Y 3/1 - 10YR 5/4 arasında değişmektedir. Derin

Çizelge 1. Profillerin morfolojik ve fiziksel özellikleri.

Table 1. Morphological and physical properties of profiles.

\begin{tabular}{|c|c|c|c|c|c|c|c|c|c|c|}
\hline Profil No & Horizon & $\begin{array}{l}\text { Derinlik } \\
(\mathrm{cm})\end{array}$ & Renk (Yaş) & $\begin{array}{c}\text { Strüktür ve Yaş } \\
\text { Kıvam }\end{array}$ & Özel Görünümler & $\begin{array}{c}\text { Kireç } \\
(\%)\end{array}$ & Kum (\%) & Silt (\%) & Kil (\%) & Bünye \\
\hline \multirow{5}{*}{ Batem1 } & Ap & $0-14$ & $2.5 Y 3 / 2$ & KOYKB; Y-P & - & 23.01 & 13.88 & 44.85 & 41.27 & $\mathrm{SiC}$ \\
\hline & A2 & $14-31$ & $2.5 \mathrm{Y} 3 / 2$ & KOYKB; ÇY-ÇP & - & 23.09 & 14.52 & 43.28 & 42,20 & $\mathrm{SiC}$ \\
\hline & $\mathrm{AC}$ & $31-49$ & $2.5 Y 3 / 2$ & Masif; Y-P & Az yoğun pas lekeleri & 23.09 & 13.52 & 48.21 & 38,27 & $\mathrm{SiCL}$ \\
\hline & $\mathrm{C} 1$ & $49-75$ & $2.5 \mathrm{Y} 4 / 3$ & Masif; Y-P & - & 27.12 & 15.52 & 48.92 & 35,56 & $\mathrm{SiCL}$ \\
\hline & $\mathrm{C} 2$ & $75+$ & $2.5 \mathrm{Y} 4 / 3$ & Masif; Y-P & - & 30.38 & 27.52 & 40.92 & 31.56 & CL \\
\hline \multirow{6}{*}{ Expo } & Ap & $0-17$ & $10 \mathrm{YR} 4 / 3$ & OOKB; ÇY-ÇP & - & 28.94 & 0.52 & 45.68 & 53.8 & SİC \\
\hline & A2d & $17-26$ & $10 \mathrm{YR} 4 / 3$ & OOKB; ÇY-ÇP & - & 29.62 & 3.52 & 35.28 & 61.2 & $\mathrm{C}$ \\
\hline & $\mathrm{AC}$ & $26-42$ & $10 \mathrm{YR} 4 / 4$ & Masif; ÇY-ÇP & Az yoğun pas lekeleri & 27.42 & 3.52 & 34.28 & 62.2 & $\mathrm{C}$ \\
\hline & $\mathrm{C} 1$ & $42-66$ & $2.5 Y 5 / 3$ & Masif; ÇY-ÇP & Az yoğun pas lekeleri & 29.17 & 6.52 & 34.21 & 59.27 & $\mathrm{C}$ \\
\hline & $\mathrm{C} 2$ & $66-108$ & $2.5 \mathrm{Y} 4 / 4$ & Masif; ÇY-ÇP & Yoğun pas lekeleri & 30.68 & 3.88 & 23.92 & 72.2 & $\mathrm{C}$ \\
\hline & $\mathrm{C} 3$ & $108+$ & $2.5 \mathrm{Y} 4 / 4$ & Masif; ÇY-ÇP & Yoğun pas lekeleri & 31.98 & 0.88 & 20.92 & 78.2 & $\mathrm{C}$ \\
\hline \multirow{6}{*}{ Misnar } & Ap & $0-18$ & $2.5 \mathrm{Y} 4 / 2$ & OOYKB; CY-ÇP & - & 24.76 & 3.88 & 39.56 & 56.56 & $\mathrm{C}$ \\
\hline & A2d & $18-38$ & $2.5 \mathrm{Y} 4 / 2$ & ZOYKB; ÇY-ÇP & - & 24.61 & 4.88 & 43.92 & 51.20 & $\mathrm{SiC}$ \\
\hline & $\mathrm{AC}$ & $38-58$ & $2.5 \mathrm{Y} 4 / 3$ & Masif; ÇY-ÇP & - & 18.00 & 8.16 & 33.64 & 58.20 & $\mathrm{C}$ \\
\hline & $\mathrm{C} 1$ & $58-77$ & $2.5 \mathrm{Y} 4 / 2$ & Masif; ÇY-ÇP & - & 12.91 & 8.88 & 32.92 & 58.20 & $\mathrm{C}$ \\
\hline & $\mathrm{C} 2$ & $77-108$ & $2.5 \mathrm{Y} 4 / 2$ & Masif; ÇY-ÇP & Az yoğun kireç miselleri & 10.67 & 7.52 & 26.28 & 66.20 & $\mathrm{C}$ \\
\hline & $2 \mathrm{Ck}$ & $108+$ & $2.5 Y 5 / 2$ & Masif; ÇY-ÇP & $\begin{array}{c}\text { Çok yoğun kireç misel ve } \\
\text { nodülleri }\end{array}$ & 20.43 & 7.52 & 35.14 & 57.34 & $\mathrm{C}$ \\
\hline \multirow{5}{*}{ Körcegözler } & Ap & $0-19$ & $10 \mathrm{YR} 4 / 3$ & OOYKB; Y-P & - & 30.61 & 5.52 & 49.28 & 45.20 & $\mathrm{SiC}$ \\
\hline & A2d & $19-48$ & $10 \mathrm{YR} 4 / 3$ & OOYKB; Y-P & - & 29.77 & 9.16 & 45.28 & 45.56 & $\mathrm{SiC}$ \\
\hline & $\mathrm{r} \quad \mathrm{C} 1$ & $48-86$ & $10 Y R 4 / 3$ & Masif; ÇY-ÇP & - & 29.55 & 7.52 & 45.28 & 47.20 & $\mathrm{SiC}$ \\
\hline & $\mathrm{C} 2$ & $86-104$ & $10 \mathrm{YR} 3 / 2$ & Masif; ÇY-ÇP & Yoğun pas lekeleri & 32.96 & 7.16 & 37.28 & 55.56 & $\mathrm{C}$ \\
\hline & $\mathrm{C} 3$ & $104+$ & $2.5 Y 5 / 3$ & Masif; ÇY-ÇP & Yoğun pas lekeleri & 32.89 & 9.52 & 40.92 & 49.56 & $\mathrm{SiC}$ \\
\hline \multirow{5}{*}{ Atçayırı } & Ap & $0-9$ & $2.5 \mathrm{Y} 4 / 2$ & KOYKB; ÇY-ÇP & - & 24.53 & 8.88 & 32.92 & 58.20 & $\mathrm{C}$ \\
\hline & $\mathrm{A} 2 \mathrm{~d}$ & $9-29$ & $2.5 Y 3 / 1$ & KOYKB; ÇY-ÇP & - & 22.63 & 7.88 & 30.92 & 61.20 & $\mathrm{C}$ \\
\hline & $\mathrm{ACg}$ & $29-45$ & $2.5 Y 5 / 2$ & Masif; ÇY-ÇP & Çok yoğun pas lekeleri & 27.80 & 8.24 & 32.56 & 59.20 & $\mathrm{C}$ \\
\hline & $\mathrm{C} 1 \mathrm{k}$ & $45-67$ & 2.5 Y $5 / 3$ & Masif; ÇY-ÇP & Yoğ. pas lek. ve yoğ. kireç konk. & 34.18 & 3.88 & 33.92 & 62.20 & $\mathrm{C}$ \\
\hline & $\mathrm{C} 2 \mathrm{k}$ & $67+$ & $2.5 \mathrm{Y} \mathrm{5/3}$ & Masif; ÇY-ÇP & Yoğ. pas lek. ve yoğ. kireç konk. & 32.81 & 6.24 & 32.56 & 61.20 & $\mathrm{C}$ \\
\hline \multirow{7}{*}{ Kelbük } & Ap & $0-15$ & $2.5 \mathrm{Y} 4 / 3$ & OOYKB; AY-AP & - & 30.53 & 9.52 & 52.92 & 37.56 & $\mathrm{SiCL}$ \\
\hline & $\mathrm{A} 2 \mathrm{~d}$ & $15-28$ & $2.5 Y 5 / 3$ & Masif; AY-AP & - & 30.68 & 11.16 & 51.28 & 37.56 & $\mathrm{SiCL}$ \\
\hline & $\mathrm{AC} 1$ & $28-50$ & $2.5 \mathrm{Y} 4 / 3$ & Masif; AY-AP & - & 32.36 & 11.52 & 57.28 & 31.20 & $\mathrm{SiCL}$ \\
\hline & $\mathrm{AC} 2$ & $50-77$ & $2.5 \mathrm{Y} 4 / 3$ & Masif; AY-AP & - & 30.84 & 9.52 & 54.92 & 35.56 & $\mathrm{SiCL}$ \\
\hline & $\mathrm{C} 1$ & $77-105$ & $2.5 Y 6 / 4$ & Masif; Y-P & - & 32.58 & 9.88 & 48.92 & 41.20 & $\mathrm{SiC}$ \\
\hline & $\mathrm{C} 2$ & $105-145$ & $2.5 \mathrm{Y} 6 / 4$ & Masif; Y-P & Çok zayıf pas lekeleri & 31.82 & 11.02 & 45.78 & 43.20 & $\mathrm{SiC}$ \\
\hline & $\mathrm{C} 3$ & $145+$ & $2.5 Y 5 / 4$ & Masif; Y-P & Çok zayıf pas lekeleri & 32.28 & 11.24 & 47.56 & 41.20 & $\mathrm{SiC}$ \\
\hline \multirow{8}{*}{ Solak } & Ap & $0-18$ & $10 \mathrm{YR} 4 / 3$ & OOYKB; AY-AP & - & 31.48 & 25.52 & 49.28 & 25.2 & $\mathrm{~L}$ \\
\hline & A2 & $18-33$ & $10 \mathrm{YR} 4 / 3$ & ZKYKB; AY-AP & - & 32.43 & 44.52 & 33.28 & 22.2 & $\mathrm{~L}$ \\
\hline & $\mathrm{AC}$ & $33-54$ & $10 Y R 4 / 3$ & Masif; AY-AP & - & 32.81 & 48.24 & 23.56 & 28.2 & SCL \\
\hline & CA & $54-70$ & $10 \mathrm{YR} 5 / 3$ & Masif; AY-AP & - & 33.19 & 19.88 & 54.92 & 25.2 & SiL \\
\hline & $\mathrm{C} 1$ & $70-89$ & $2.5 \mathrm{Y} 4 / 3$ & Masif; AY-AP & - & 31.14 & 31.88 & 43.92 & 24.2 & $\mathrm{~L}$ \\
\hline & $\mathrm{C} 2$ & $89-112$ & $2.5 Y 5 / 3$ & Masif; AY-AP & Yoğun pas lekeleri & 33.87 & 21.88 & 45.92 & 32.2 & CL \\
\hline & $\mathrm{C} 3$ & $112-134$ & $2.5 Y 5 / 3$ & Masif; ÇY-ÇP & Yoğun pas lekeleri & 32.89 & 11.88 & 47.92 & 40.2 & $\mathrm{SiC}$ \\
\hline & $\mathrm{C} 4$ & $134+$ & $2.5 Y 5 / 3$ & Masif; ÇY-ÇP & Çok yoğun pas lekeleri & 34.25 & 7.88 & 51.92 & 40.2 & $\mathrm{SiC}$ \\
\hline \multirow{4}{*}{ Batem2 } & Ap & $0-15$ & $10 \mathrm{YR} 4 / 3$ & OOYKB; Y-P & - & 22.94 & 36.80 & 34.64 & 28.56 & $\mathrm{CL}$ \\
\hline & $\mathrm{A} 2$ & $15-29$ & $10 \mathrm{YR} 4 / 3$ & OOYKB; Y-P & - & 23.01 & 25.52 & 39.92 & 34.56 & CL \\
\hline & $\mathrm{C} 1$ & $29-52$ & $10 \mathrm{YR} 4 / 3$ & Masif; AY-AP & - & 24.53 & 35.16 & 35.28 & 29.56 & CL \\
\hline & $\mathrm{C} 2$ & $52+$ & 10YR 4/4 & Masif; AY-AP & Çok seyrek kireç miselleri & 24.15 & 27.80 & 37.64 & 34.56 & $\mathrm{CL}$ \\
\hline & & & $\mathrm{m}: \mathrm{AY}$ & öşeli b & OKB: Orta orta yarı köşeli b & & Orta & yarı kö & i blok & \\
\hline
\end{tabular}


profillere sahip bu serilerin A horizonlarında köşeli blok veya yarı köşeli blok strüktürlerin gelişimi görülürken, C horizonlarında ise strüktür, masif olarak tanımlanmıştır. Kıvam özellikleri, içerdikleri kil miktarına bağlı olarak nemli iken sıkı, yaş iken yapışkan veya çok yapışkan çok plastik olarak tespit edilmiştir. Çalışma alanının kuzey batı kesimlerinde Expo, Körcegözler ve Atçayırı serilerinin alt horizonlarında az yoğundan çok yoğuna doğru değişen şiddetlerde pas lekeleri görülmüştür. Batem 1, Misnar ve Kelbük serilerinde daha derinlerde az yoğunlukta pas lekeleriyle birlikte seyrek ya da yoğun kireç konkresyonları gözlenmiştir.

Çalışma alanındaki diğer bir fizyografik ünite olan nehir sırtı fizyografyası Tehnelli deresi ve Aksu çayının geçmişteki taşkınları sonucunda akarsu yatağının her iki kıyısındaki alanlarda daha kaba olan sedimentlerin depolanması sonucunda oluşmuş arazileri kapsamaktadır. Bu araziler düz veya düze yakın eğimde olup, geçirgenlikleri de oldukça yüksektir. Tekstürlerinin kaba olması nedeni ile toprak serilerinde drenaj problemi yaşanmamaktadır. Tıpkı taşkın düzlügü topraklarında olduğu gibi bu ünitede de topraklar genç olduklarından yeterli profil gelişimi gerçekleşememiş bunun sonucunda A-C horizon dizilimli topraklar oluşmuştur. Tanımlanan toprak serileri içerisinde sadece Solak serisi bu fizyografyada bulunmaktadır. Solak toprak serisinde yapılan morfolojik tanımlar ve laboratuvarda yapılan fiziksel analiz sonuçları Çizelge 1'de verilmiştir. $\mathrm{Bu}$ fizyografyaya ait topraklar çalışma alanının \%11.5'ini bir diğer ifade ile 186.2 ha'ını oluşturmaktadır. Yapılan profil tanımlama çalışmalarında seriye ait toprak renginin üst horzonlarda $10 \mathrm{YR}$ 4/3 iken alt horizonlarda $2.5 \mathrm{Y}$ $5 / 3$ olarak değiştiği tespit edilmiştir. Derin bir profile sahip olan bu seride strüktür, A horizonunda yarı köşeli blok, C horizonunda masif olarak belirlenmiştir. Bu serilerdeki kıvam özellikleri kuru iken sert, nemli iken sıkı, yaş iken içerdikleri düşük kil miktarına bağlı olarak, az yapışkan az plastik veya yapışkan değil plastik değil olarak tespit edilmiştir. Çalışma alanının doğusunda yer alan Solak serisi profilinde yaklaşık 90 $\mathrm{cm}$ 'den sonra yoğun pas lekeleri görülmüştür.

Çalışma alanında kısıtlı bir bölgede bulunan yan dere alüviyalleri fizyografyası Aksu çayının çok eski dönemlerinde, traverten düzlükleri üzerine taşıdığı malzemeleri depolaması ile oluşmaya başlamıştır. Yakın geçmişte ve günümüzde ise Aksu çayı ve Tehnelli derelerinin yüksek arazilerden, düzlüklere ulaşan yan dere kollarıyla yukarı havzalardan getirdikleri farklı nitelikte materyalleri kısa mesafeler içerisinde yeniden depolamalarıyla yan dere alüviyallerini oluşturmuştur. $\mathrm{Bu}$ fizyografya üzerindeki topraklar genç olmaları sebebiyle, A-C horizon dizilimine sahip kireçli topraklardır. Yapılan toprak tanımlama çalışmalarında taşkın düzlüğü fizyografyası üzerinde sadece Batem 2 toprak serisi tespit edilmiştir. Batem 2 serisine ait yapılan morfolojik tanımlar ve laboratuvarda yapılan fiziksel analiz sonuçları Çizelge 1'de verilmiştir. Çalışma alanında yan dere alüviyali fizyografyası üzerinde gelişen bu toprak serisi $\% 2.7$ (440.3 da)'da dağılım göstermektedir. Profilde renk 10YR $4 / 3$ ve 10 YR $4 / 4$ olarak tanımlanmıştır. Tanımlanan toprak profilinin A horizonunda strüktür yarı köşeli blok C horizonunda masif olarak tespit edilmiştir. Kıvam özellikleri kil içeriğinin yüksek olduğu katmanlarda kuru iken sert, nemli iken sıkı ve yaş iken de çok yapışkan çok plastik, kil içeriğinin düşük olduğu katman ve profillerde ise yapışkan değil plastik değil olarak tespit edilmiştir. Çalışma alanının güney kesimlerinde tespit edilen Batem 2 serisi topraklarının $52 \mathrm{~cm}$ 'sinden sonra çok seyrek kireç miselleri görülmüştür.

\section{2. Çalışma alanı toprakları arazi yetenek sınıflaması}

Araştırma alanında yapılan detaylı toprak etüdleri ve arazi değerlendirme çalışmalarının her birisi, toprakların korunması ve üretkenliklerinin devamının sağlanabilmesi için yapılan çalışmalardır. Bu kapsamda bazı planlamaların yapılması ve bunların 1şığında yönetim şekillerinin oluşturulması için, toprakların farklı kullanımlara uygunluklarını gösteren ve teknik bir sınıflama sistemi olan arazi yetenek sınıflamasının yapılması gerekmektedir. $\mathrm{Bu}$ kapsamda çalışma alanı toprakları için yapılan arazi yetenek sınıflarının alansal dağılımları ve toplam alandaki yüzdeleri Çizelge 2'de haritası ise Şekil 2'de verilmiştir.

Çizelge 2. Arazi yetenek sınıfları alansal dağılımı.

Table 2. Spatial distribution of land capability classes.

\begin{tabular}{llc}
\hline Arazi yetenek sinıfları & Alan (ha) & Alan (\%) \\
\hline I & 160.0 & 9.8 \\
IIs & 583.3 & 35.9 \\
\hline II sw & 150.1 & 9.2 \\
\hline III s & 314.0 & 1.9 \\
\hline III sw & 277.0 & 17.0 \\
\hline III ws & 218.7 & 13.5 \\
\hline Etüd Dışı & 204.8 & 12.6 \\
\hline Toplam & 1625.3 & 100 \\
\hline
\end{tabular}

Yapılan sınıflandırma çalışmasında, arazilerin genellikle II. ve III. sınıf oldukları tespit edilmiştir. arazi yetenek sinıflamasına göre I. sınıf araziler 160 ha, II. sınıf araziler 733.4 ha ve III. sınıf araziler 527.1 ha olarak hesaplanmıştır. IV, VI, VII ve VIII. sınıf araziler olacak kadar sınırlayıcı faktörler olmadığı için bu dört sınıf tespit edilememiştir.

Fizyografik üniteler üzerindeki toprak serilerinin bulunduğu arazilerin hangi arazi yetenek sınıflarından oluştuğu ve bunların alanları Çizelge 3'de verilmiştir.

Taşkın düzlüğü fizyografyası üzerinde tanımlanan toprak serileri genel olarak II. ve III. Sınıf arazi yetenek sınıflarında yer almışlardır. Bu fizyografyada tanımlanan arazi yetenek sınıfları; IIs, IIsw, IIIs, IIIsw ve IIIws şeklindedir. Sinıflama yapilırken bu toprak serilerinin II. ve III. siniflarda tanımlanmasına neden olan başlıca sebep, profillerde pas lekelerinin görülmesidir. Özellikle Expo, Mısnar ve Atçayırı serilerinin bazı yerlerinde drenaj bozuklukları 0-30 $\mathrm{cm}$ de bile tespit edilebilmiştir. $\mathrm{Bu}$ fizyografya üzerinde tanımlanmış Körcegözler ve Kelbük serilerinde genel olarak Fena $(30-60 \mathrm{~cm})$ ya da Orta $(60-90 \mathrm{~cm})$ drenaj, Batem 1 serisinde Yetersiz (90$100 \mathrm{~cm})$ ya da İyi $(100+\mathrm{cm})$ drenaj tespit edilmiştir. Nehir sırtı fizyografyası üzerinde tanımlanan Solak serisi toprakları ise araştırma alanının en problemsiz toprakları olarak tespit edilmiştir. Bu seri sınırları içerisindeki toprakların bir kısmı I. sınıf araziler olarak tanımlanırken bir kısmı da IIs sınıfına dahil edilmiştir. Yan dere alüviyalleri üzerinde gelişen Batem 2 serisi topraklarının tamamı IIs olarak tanımlanmıştır.

\section{Sonuç}

Çalışma alanı, esas itibari ile Aksu çayı ve Tehnelli deresinin oluşturduğu birikinti yelpazesi üzerindeki alüviyal materyallerden oluşmuştur. Genel olarak alüviyal arazilerde çok farklı fizyografik üniteler bulunabilmekle beraber araştırma alanı üzerinde taşkın düzlükleri, nehir sırtları ve taşkın 


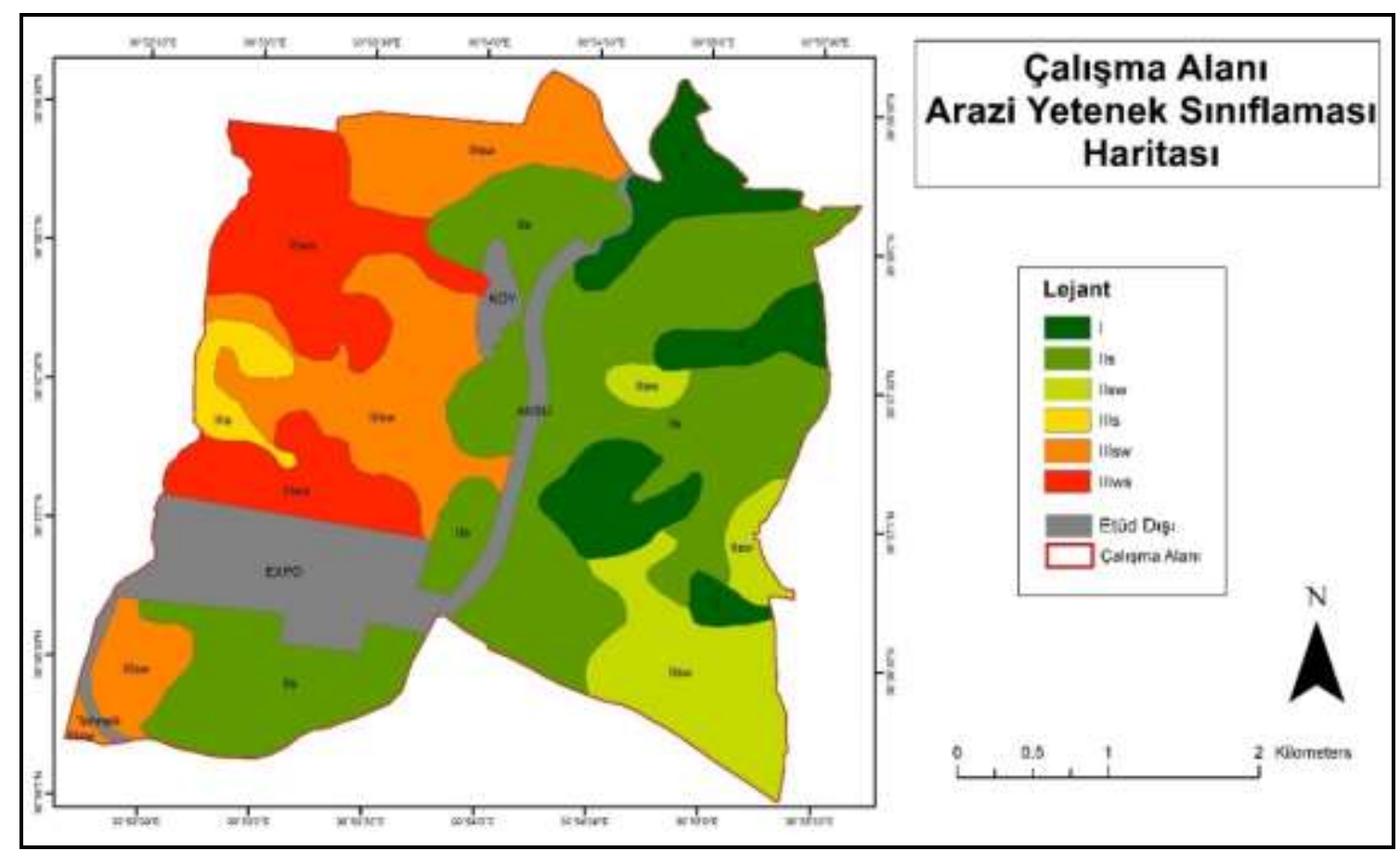

Şekil 2. Çalışma alanının arazi yetenek sınıflaması haritası.

Figure 2. Land capability classification map of the study area.

Çizelge 3. Fizyografya ve arazi yetenek sınıfları.

Table 3. Physiography and land ability classes.

\begin{tabular}{llll}
\hline Fizyografik Ünite & Toprak serisi & Arazi yetenek sinıfları & Alan (ha) \\
& Batem 1 & IIs & 101.01 \\
& Expo & IIIs, IIIsw, IIIws & 130.98 \\
Taşkın Düzlüğü & Misnar & IIIsw, IIIws & 81.53 \\
& Körgecegözler & IIIsw, IIIws & 162.22 \\
& Atçayırı & IIIsw, IIIws & 149.16 \\
& Kelbük & IIs, IIsw, IIIsw & 570.09 \\
\hline Nehir Sirtı & Solak & I, IIs & 186.26 \\
\hline Yan Dere Alüviyali & Batem 2 & IIs & 44.03 \\
\hline
\end{tabular}

düzlüklerine bağlanan yan dere alüviyallerinden oluşan fizyografyalara rastlanılmıştır. Arazide yapılan ve laboratuvarla desteklenen veriler söz konusu fizyografyalardaki değişimlerle, toprak özellikleri arasında sıkı bir ilişki olduğunu göstermiştir.

Araştırma alanı olan Solak köyü arazilerinin büyük bir bölümünün oluşumunda daha çok Aksu çayının etkili olduğu ve en yaygın fizyografik ünitenin ise taşkın düzlüğü arazilerinin olduğu tespit edilmiştir. $\mathrm{Bu}$ araziler Kuvaterner dönemin ürünleri olduklarından, oldukça genç oluşumlardır. Genç olmaları sebebiyle toprak profilini geliştirecek prosesler henüz yeteri kadar çalışamamış ve bu nedenle profilleri boyunca A ve C horizonları dışında başka tanımlayıcı horizonları henüz gelişememiştir. Bu fizyografik ünitede yer alan serilerin tamamı düz ve düze yakın arazilerdir. Aksu alüviyalinin alt zonlarında daha çok sedimantasyon faaliyetleri görüldüğünden bu fizyografyada depolanan alüviyal materyal \%78'lere varan kil içeriğine sahiptir. Bunun yanı sıra arazilerin düz topoğrafyada bulunmaları, toprak serilerinin bazılarında hafiften şiddetliye kadar değişen düzeylerde drenaj problemi bulunmaktadır. Tanımlanan toprak serilerine göre değişmekle birlikte, yaklaşık $45-50 \mathrm{~cm}$ den sonra görülen pas lekeleri bu topraklarda drenaj probleminin zaman zaman bazı tarımsal üretim modellerini kısıtlayacağını göstermektedir. $\mathrm{Bu}$ nedenedir ki bu fizyografyada tanımlanan arazilerde yetenek sinıflaması genellikle II. ve III. sınıf olarak tanımlanmıştır. Özellikle III. sınıf arazilerin hepsi bu fizyografya üzerinde tespit edilmiştir. Bunların genelinde toprak ile ilgili yetersizlikler (tekstür, eğim) "s" ve kültür bitkilerinin gelişmesine engel olan profildeki fazla su (drenaj sorunu, taşkın zararı ve tehlikesi) "w" olarak haritalandırılmıştır.

Çalışma alanında tanımlanan diğer iki fizyografik ünite olan nehir sırtı ve yan dere alüviyalleri üzerinde gelişen profillerde tekstür, taşkın düzlüğü fizyografyasına göre daha hafif bünyeli olarak tanımlanmıştır. Nehir sırtı fizyografyasını tanımlayan Solak serisi topraklarının profillerinde $90 \mathrm{~cm}$ 'den sonra görülen pas lekeleri, yapılan grid yöntemi ve burgu kontrol noktaları tanımlamalarında sınırlı bir alanda tespit edilmiştir. Nehir sırtı ve yan dere alüviyalleri fizyografyalarındaki arazilerin yetenekleri genel olarak I. ve II. sınıf olarak sınıflandırılmıştır. $\mathrm{Bu}$ fizyografyalarda tanımlanmış serilerde sadece üst toprak tekstürünün siltli killi tın (SiCL) olarak tespit edildiği alanlarda arazi yetenek sınıfi, IIs olarak sınıflandırılmış diğer alanlar I. sınıf olarak tanımlanmıştır. 
Tarımsal faaliyetlerin yoğun olarak yapıldığı çalışma alanı arazilerinde yöreye uygun yapılacak olan her türlü kullanımda toprağın tekstür özelliğine ve drenaj koşullarına dikkat edilmelidir. Özellikle sulu tarım uygulamalarından kaynaklanan zaman zaman taban suyunun yükselmesiyle sonuçlanan sorunlar oluşabileceği de görülmektedir. Üretim sürecinde seçilecek olan ürün deseni, toprak işleme şekli ve zamanı, sulama miktarı ve sıklığ 1 ve hatta verilecek olan bitki besin elementlerinin formlarının dahi belirlenmesiyle sürdürülebilir tarımsal verimlilik sağlanmasının yanı sıra yöre çiftçilerine de ekonomik açıdan yüksek karlılık sağlanmış olacaktır.

Genel olarak alüviyal araziler en verimli tarımsal araziler olmalarının yanı sıra çeşitli sorunları da içerirler. Bu sorunlar, taşkın düzlügü fizyografyasında yüksek kil içeriği ve drenaj problemleri iken nehir sırtı fizyografyasında ise çakıl veya kum bantları, hafif bünyeli topraklar, düşük su tutma kapasitesi, bitki besin maddelerinin yıkanmasıdır. Ancak bu sorunlar bile arazilerin I., II. ve III. sınıf olarak tanımlanmalarına engel olamamıştır.

Sonuç olarak, hatalı kullanımlar, amaç dışı kullanımlar ve diğer pek çok sebepten dolayı hızla kaybolmaya devam eden en değerli kaynaklarımızdan olan topraklar, tanınmalı ve özellikleri dikkate alınarak yetenekleri doğrultusunda kullanılmalıdır. Ancak böylelikle binlerce yılda oluşan toprakların, sürdürülebilirlikleri sağlanabilir. $\mathrm{Bu}$ noktadan hareketle ülkemizde, tarımsal potansiyeli yüksek tarım arazilerine öncelik verilerek, tüm arazilerimizin detaylı etütleri ivedilikle tamamlanmalı ve arazilerimiz tarım ve tarım dışı alanlarda yetenekleri dahilinde kullanılmalıdır. Belirlenen kullanımlar yasalarla desteklenmeli ve asla amaç dışı kullanımlara izin verilmemelidir.

\section{Teşekkür}

Bu çalışma, FBA-2016-1536 numaralı Araştırma Projesinin bir bölümüdür. Katkılarından dolayı Akdeniz Üniversitesi Bilimsel Araştırma Projeleri Yönetim Birimine teşekkür ederiz.

\section{Kaynaklar}

Altunbaş S, Gözükara G, Şimşek O, Buyurgan K (2017) Aksu ovası topraklarının arazi kulanım planlamasında kullanılmak üzere temel toprak etütlerinin yapılması ve özelliklerinin belirlenmesi. Akdeniz Üniversitesi Bilimsel Araştırma Projeleri, Normal Araştırma Projesi, Antalya.

Baykal H, Baykal T (2008) Küreselleşen dünya'da çevre sorunları. Mustafa Kemal Üniversitesi Sosyal Bilimler Enstitüsü Dergisi 5(9): $1-17$.

Bouyoucos GH (1951) A recalibration of the hydrometer method for making mechanical analysis of soils. Agronomy Journal 43: 434438.

Demirel BÇ (2017) Hızlı büyüme potansiyeline sahip yerleşim alanlarının detaylı toprak etütleri ve arazi değerlendirmeleri: Mustafalar köyü örneği, Adana. Yüksek Lisans Tezi, Çukurova Üniversitesi Fen Bilimleri Enstitüsü, Adana.

Dinç U, Şenol S (2013) Toprak etüd ve haritalama. Çukurova Üniversitesi Ziraat Fakültesi Genel Yayın No: 161, Ders Kitapları Yayın No: A-50, Çukurova Üniversitesi Ziraat Fakültesi Ofset Atölyesi, Adana.

DPT (2005) Devlet planlama teşkilatı, sekizinci beş yıllık kalkınma planı. Tarımsal politikalar ve yapısal düzenlemeler özel ihtisas komisyonu raporu, Ankara.

FAO (1985) Guidelines land evaluation for irrigated agriculture. FAO Soils Bulletin 55, FAO, Rome.
Gözükara G (2019) Eski göl tabanlarındaki zamansal ve mekansal değişimlerin toprak oluşumuna etkileri. Doktora Tezi, Akdeniz Üniversitesi Fen Bilimleri Enstitüsü, Toprak Bilimi ve Bitki Besleme Anabilim Dalı, Antalya.

Gözükara G, Altunbaş S, Sarı M (2019) Mekansal değişimin alüviyal fanlar üzerinde oluşan toprakların özelliklerine etkisi. Mediterranean Agricultural Sciences 32(3): 425-435.

Karaman MR, Susam T, Turan M, Tutar A, Şahin S (2012) Çilek tarımı yapılan arazide uzaysal doğal organik madde deģişimlerinin jeoistatistiksel yöntemlerle belirlenmesi. Sakarya Üniversitesi, Fen Edebiyat Dergisi 14(1): 197-205.

Koca YK (2014) Toprak etüdlerinde uzman gereksinimini azaltacak yöntemlerin adana ili örneğinde araştırılması. Doktora Tezi, Çukurova Üniversitesi Fen Bilimleri Enstitüsü, Adana.

Sarı M (2015) Taşınmış ana materyal ile yer şekilleri arasındaki ilişkiler (Ed. Şenol S., Küsek G., Sarı M., Kurucu Y.) Toprak Etüd Haritalama El Kitabı. Ankara, s. 52-109.

Schlichting E, Blume E (1966) Bodenkundliches praktikum. Verlag Paul Parey, Hamburg und Berlin: Preis: Kartoniert.

Soil Survey Staff (1993) Soil survey manual. US Department of Agriculture, Handbook No. 18, Washington DC, USA, pp. 437.

Soil Survey Staff (1998) Keys to soil taxonomy. Natural Resources Conservation Service, Eighth Edition. USDA, Washington D.C., pp. 326.

Şenol S, Tekeş Y (1995) Arazi değerlendirme ve arazi kullanım planlaması amacıyla geliştirilmiş bir bilgisayara modeli. Türkiye Toprak İlmi Derneği, İlhan Akalan Toprak ve Çevre Sempozyumu, Yayın No:7, Ankara, s. 204-210.

Vacca A, Loddo S, Melis MT, Funedda A, Puddu R, Verona M, Fanni S, Fantola F, Madrau S, Marrone VA, Serra G (2014) A gis based method for soil mapping in sardinia, Italy: a geomatic approach. Journal of Environmental Management 138: 87-96. 